\title{
Maintaining and restoring cytoplasmic male sterility systems in pepper (Capsicum annuum L.)
}

\author{
Y. Ma ${ }^{1,2^{*}}$, W. Huang ${ }^{1,2^{*}}$, J.-J. Ji ${ }^{1,2}$, Z.-H. Gong ${ }^{1,2}$, C.-C. Yin ${ }^{1}$, S.S. Ahmed \\ and Z.-L. Zhao ${ }^{1}$ \\ ${ }^{1}$ College of Horticulture, Northwest A\&F University, Yangling, \\ Shaanxi, China \\ ${ }^{2}$ State Key Laboratory for Stress Biology of Arid Region Crop, \\ Northwest A\&F University, Yangling, Shaanxi, China \\ *These authors contributed equally to this study. \\ Corresponding author: Z.-H. Gong \\ E-mail: zhgong@nwsuaf.edu.cn
}

Genet. Mol. Res. 12 (3): 2320-2331 (2013)

Received March 7, 2012

Accepted August 20, 2012

Published January 4, 2013

DOI http://dx.doi.org/10.4238/2013.January.4.8

\begin{abstract}
We studied the efficiency of maintaining and restoring cytoplasmic male sterility (CMS) systems in pepper (Capsicum annuum L.). An $R f$-linked molecular marker was employed to analyze the interaction between 6 CMS lines (A), 5 maintainers (B), and 6 restorers $(\mathrm{C})$. Sterility was maintained in the matings of lines $201 \mathrm{~A} \times 200 \mathrm{~B}, 203 \mathrm{~A} \times 200 \mathrm{~B}, 206 \mathrm{~A} \times 200 \mathrm{~B}, 200 \mathrm{~A} \times 201 \mathrm{~B}, 206 \mathrm{~A} \times$ 201B, 200A x 202B, 200A x 203B, 200A x 206B, and 201A x 206B. All 6 restorers restored the fertility of lines 200A, 202A, 203A, and $204 \mathrm{~A}$, except that $213 \mathrm{C}$ could not restore the fertility of lines $200 \mathrm{~A}$ and 204A. However, the 6 restorers had diverse restoring abilities in individual CMS lines. The $R f$-linked molecular marker was amplified by PCR in lines $207 \mathrm{C}, 208 \mathrm{C}$, and $213 \mathrm{C}$. This DNA marker was only found in the F1 hybrids M39, M14, M19, M25, M13, M20, and M22. We conclude that the restorers $208 \mathrm{C}$ and $207 \mathrm{C}$ can transmit the $R f$
\end{abstract}


gene or the $R f$-linked marker to F1 hybrids.

Key words: Pepper; Cross-combination; Fertility investigation; $R f$-linked molecular marker

\section{INTRODUCTION}

Cytoplasmic genetic male sterility (CMS) is a method that is widely used for producing F1 hybrid seeds as well as the study of nucleo-cytoplasmic interactions (Budar et al., 2003; Hanson and Bentolila, 2004; Chase, 2007). The CMS three-line-hybridizing method is an important method for heterosis utilization of the crop. The genotype of the CMS line (A), maintainer (B), and restorer (C) is $S r f r f, N r f r f, S / N R F R F$, or $S R F r f$, respectively (Guo, 2001). CMS is the result of the coaction of the karyogenes and the cytogenes. The nuclear gene of the CMS line is controlled by the recessive gene, while the novel expression of the orf gene in the mitochondrial genome inhibits the plant from producing normal pollen (Hanson, 1991; Linke and Borner, 2005). The restoration of the fertility of the CMS line is controlled by the $R f$ gene (Schnable and Wise, 1998; Hanson and Bentolila, 2004; Horn, 2006).

Male sterility in pepper (Capsicum annuum L.) was first reported by Peterson (1958). The inheritance of the pepper is quite complex, as there are 2 types of male sterility in pepper; genic male sterility is controlled by the nuclear gene and CMS is controlled by both the karyogene and the cytogene. Meanwhile, CMS is not only inherited stably, but also is affected by the environment. Both Peterson (1958) and Shifriss (1997) reported that the expression of the male-sterility gene could be affected by environmental temperature (Shifriss and Guri, 1979). Partial sterility of pollen, which may be affected by the environment or controlled by other specific genes, was first reported by Zhang et al. (2000). Thus, changes in temperature may lead to alterations in fertility ranging from complete sterility to partial fertility, which may also lead to CMS lines self-crossing or being crossed as the male parent (Gergely et al., 2006). Therefore, the application of the CMS line is based on the understanding of the genetic characteristics of the CMS line and the relationship between maintaining and restoring.

Regarding the developing of molecular markers, partial markers were found and applied to fertility selection in pepper. For example, Peterson (1958) first reported that there were multiple alleles of the restoring gene (Rf) in pepper. Kim et al. (2001) and Kim and Kim (2005) found that there were differences in the mtDNA region between the coxII and atp6-2 gene of the maintainer and CMS line, and then identified 2 sequence-characterized amplified region (SCAR) markers related to CMS. Zhang et al. (2000) selected two $R$-linked random amplified polymorphism DNA markers, OP131400 $(0.37 \mathrm{cM})$ and OW18800 $(8.12 \mathrm{cM})$, which were converted to CRF-SCAR [OPT-02/570 (5 cM)] by Lee et al. (2004) and Gulyas et al. (2006). The exploitation of this molecular marker can speed up the process of CMS selection and application of CMS in pepper, which can improve the breeding effect.

We selected and bred several types of CMS lines as well as their related maintainers and restorers by the combination of interspecific crossing and the induced mutation technique (Gong et al., 2008); however, the relationship between maintaining and restoring is unknown. In this study, we aimed to reveal the relationship between the CMS line, the related maintainer, and the restorer by field crossing, surveys, and indoor evaluation. Meanwhile, we analyzed the differences of the restoring gene among different materials using the CRF-SCAR marker (Gulyas et al., 2006). These 
data will provide the theoretical foundation for the application of the CMS system.

\section{MATERIAL AND METHODS}

\section{Plant materials}

The experiment employed 5 CMS lines (A; 200A, 201A, 202A, 203A, and 206A), 5 near-isogenic maintainers (B; 200B, 201B, 202B, 203B, and 206B), an additional CMS line (204A), and 6 restorers $(\mathrm{C} ; 207 \mathrm{C}, 208 \mathrm{C}, 209 \mathrm{C}, 211 \mathrm{C}, 213 \mathrm{C}$, and $214 \mathrm{C})$ of the pepper $(C$. annuит L.), which were provided by the pepper research team at Northwest A\&F University (Table 1). Each pair of A and B differed in cytoplasm types; these were used for performing crosses and analyzing the relationship between maintaining and restoring.

\begin{tabular}{|c|c|c|c|c|}
\hline Lines & Genotype & Phenotype & Fruit type & Line function \\
\hline $200 \mathrm{~A}$ & $S(m s m s)$ & Sterile & $\mathrm{H}$ & CMS, A line \\
\hline $201 \mathrm{~A}$ & $S(m s m s)$ & Sterile & $\mathrm{H}$ & CMS, A line \\
\hline $202 \mathrm{~A}$ & $S(m s m s)$ & Sterile & $\mathrm{H}$ & CMS, A line \\
\hline $203 \mathrm{~A}$ & $S(m s m s)$ & Sterile & $\mathrm{H}$ & CMS, A line \\
\hline $204 \mathrm{~A}$ & $S(m s m s)$ & Sterile & $\mathrm{H}$ & CMS, A line \\
\hline $206 \mathrm{~A}$ & $S(m s m s)$ & Sterile & $\mathrm{S}$ & CMS, A line \\
\hline 200B & $N(m s m s)$ & Fertile & $\mathrm{H}$ & CMS, maintainer, $\mathrm{B}$ line \\
\hline 201B & $N(m s m s)$ & Fertile & $\mathrm{H}$ & CMS, maintainer, B line \\
\hline 202B & $N(m s m s)$ & Fertile & $\mathrm{H}$ & CMS, maintainer, B line \\
\hline 203B & $N(m s m s)$ & Fertile & $\mathrm{H}$ & CMS, maintainer, B line \\
\hline 206B & $N(m s m s)$ & Fertile & $\mathrm{S}$ & CMS, maintainer, B line \\
\hline $207 \mathrm{C}$ & $N(R f R f)$ & Fertile & $\mathrm{H}$ & CMS, restorer, $\mathrm{C}$ line \\
\hline $208 \mathrm{C}$ & $N(R f R f)$ & Fertile & $\mathrm{H}$ & CMS, restorer, $\mathrm{C}$ line \\
\hline $209 \mathrm{C}$ & $N(R f R f)$ & Fertile & $\mathrm{S}$ & CMS, restorer, $\mathrm{C}$ line \\
\hline $211 \mathrm{C}$ & $N(R f R f)$ & Fertile & $\mathrm{S}$ & CMS, restorer, $\mathrm{C}$ line \\
\hline $213 \mathrm{C}$ & $N(R f R f)$ & Fertile & $\mathrm{S}$ & CMS, restorer, $\mathrm{C}$ line \\
\hline $214 \mathrm{C}$ & $S(R f R f)$ & Fertile & $\mathrm{S}$ & CMS, restorer, $\mathrm{C}$ line \\
\hline
\end{tabular}

$\mathrm{H}=$ hot pepper; $\mathrm{S}=$ sweet pepper.

\section{Crossing test}

The 5 maintainers (200B, 201B, 202B, 203B, and 206B) were crossed separately to 5 CMS lines (200A, 201A, 202A, 203A, and 206A; A x B), and 6 restorers (207C, 208C, 209C, 211C, 213C, and 214C) were crossed separately to 4 CMS lines (200A, 202A, 203A, and 204A; Table 2). All F1 hybrids ( $M$ is prefixed for the code of each cross-combination) of 40 crossing combinations were harvested in September 2010. The following April, all F1 hybrid seeds were grown in a greenhouse, and the fertility of the F1 hybrids was identified from the early stage of anthesis.

\section{Pollen assay}

\section{Field statistical experiment}

In the blooming stage of anthesis, 5 flowers were randomly selected to evaluate the F1 hybrid fertility according to the method of Gulyas et al. (2006). 
Table 2. Crossing combinations of cytoplasmic male sterility system in pepper.

\begin{tabular}{|c|c|c|c|c|c|c|c|}
\hline Hybrid combination & Code & Hybrid combination & Code & Hybrid combination & Code & Hybrid combination & Code \\
\hline $206 \mathrm{~A} \times 200 \mathrm{~B}$ & M1 & $202 \mathrm{~A} \times 207 \mathrm{C}$ & M14 & $201 \mathrm{~A} \times 206 \mathrm{~B}$ & M28 & $203 \mathrm{~A} \times 207 \mathrm{C}$ & M39 \\
\hline $206 \mathrm{~A} \times 201 \mathrm{~B}$ & M2 & $206 \mathrm{~A} \times 203 \mathrm{~B}$ & M15 & $201 \mathrm{~A} \times 203 \mathrm{~B}$ & M29 & $203 \mathrm{~A} \times 211 \mathrm{C}$ & M40 \\
\hline $202 \mathrm{~A} \times 201 \mathrm{~B}$ & M3 & $202 \mathrm{~A} \times 214 \mathrm{C}$ & M16 & $201 \mathrm{~A} \times 202 \mathrm{~B}$ & M30 & $203 \mathrm{~A} \times 206 \mathrm{~B}$ & M42 \\
\hline $200 \mathrm{~A} \times 211 \mathrm{C}$ & M5 & $200 \mathrm{~A} \times 201 \mathrm{~B}$ & M18 & $204 \mathrm{~A} \times 214 \mathrm{C}$ & M31 & $203 \mathrm{~A} \times 201 \mathrm{~B}$ & M43 \\
\hline $201 \mathrm{~A} \times 200 \mathrm{~B}$ & M7 & $200 \mathrm{~A} \times 207 \mathrm{C}$ & M19 & $200 \mathrm{~A} \times 209 \mathrm{C}$ & M33 & $200 \mathrm{~A} \times 203 \mathrm{~B}$ & M44 \\
\hline $203 \mathrm{~A} \times 202 \mathrm{~B}$ & M8 & $204 \mathrm{~A} \times 208 \mathrm{C}$ & M20 & $203 \mathrm{~A} \times 213 \mathrm{C}$ & M34 & $200 \mathrm{~A} \times 206 \mathrm{~B}$ & M45 \\
\hline $203 \mathrm{~A} \times 200 \mathrm{~B}$ & M9 & $204 \mathrm{~A} \times 209 \mathrm{C}$ & M21 & $200 \mathrm{~A} \times 214 \mathrm{C}$ & M35 & $206 \mathrm{~A} \times 202 \mathrm{~B}$ & M46 \\
\hline $202 \mathrm{~A} \times 206 \mathrm{~B}$ & M10 & $200 \mathrm{~A} \times 208 \mathrm{C}$ & M22 & $203 \mathrm{~A} \times 209 \mathrm{C}$ & M36 & $200 \mathrm{~A} \times 202 \mathrm{~B}$ & M41 \\
\hline $202 \mathrm{~A} \times 209 \mathrm{C}$ & M11 & $204 \mathrm{~A} \times 211 \mathrm{C}$ & M23 & $204 \mathrm{~A} \times 213 \mathrm{C}$ & M37 & $200 \mathrm{~A} \times 213 \mathrm{C}$ & M24 \\
\hline $202 \mathrm{~A} \times 208 \mathrm{C}$ & M13 & $203 \mathrm{~A} \times 214 \mathrm{C}$ & M26 & $203 \mathrm{~A} \times 208 \mathrm{C}$ & M38 & $204 \mathrm{~A} \times 207 \mathrm{C}$ & M25 \\
\hline
\end{tabular}

\section{Analysis of pollen quantity}

The pollen quantity was measured according to the method described by Wang et al. (2008). One hundred anthers from 30 large flowers of each combination were put into vials to desiccate the anther. When the pollen was fully released, $5 \mathrm{~mL} 1 \%$ sodium hexametaphosphate was added, and the vial was shaken to resuspend the pollen. After resuspending the pollen, a drop of the suspension was added to a counting chamber to evaluate the quantity of pollen. Each experiment was repeated 6 times and the values obtained for each experiment were averaged. The pollen quantity of each anther $(\mathrm{N})$ was equal to the medium value of the 6 values, which were calculated in accordance with the following formula:

$\mathrm{N}=($ total number of pollen grains in 400 grids $\times 10,000 \times 5 \times 3) / 100$

\section{Analysis of pollen germination}

After drying in the shade, pollen grains isolated from flowers were germinated in vitro in culture medium $(0.01 \%$ boric acid $+10 \%$ sucrose $+1 \%$ agar $)$ at $25^{\circ} \mathrm{C}$ in the dark (Ye, 2010). The percentage of pollen germination was measured at 3, 6, 18, and $21 \mathrm{~h}$. For each experiment, 6 fields were randomly observed by light microscope. The pollen germination rate was calculated in accordance with the following formula:

Germination rate $(\%)=$ number of germinated pollen grains / total pollen grains $\mathrm{x} 100$

\section{Fruit setting and seed analysis}

Ten flowers were randomly marked in each plant to measure the fruit-setting rate and the number of seeds in each fruit; finally, the median value was obtained.

\section{$R f$-linked molecular marker analysis}

Total DNA was extracted from the fresh leaves of each plant (Walbot and Warren, 1988). The primers were designed according to the method of Gulyas et al. (2006). The marker was prepared using the following PCR protocol: an initial denaturation at $95^{\circ} \mathrm{C}$ for $5 \mathrm{~min}, 40$ cycles of amplification, each consisting of $95^{\circ} \mathrm{C}$ for $45 \mathrm{~s}$, annealing at $62^{\circ} \mathrm{C}$ for $45 \mathrm{~s}, 72^{\circ} \mathrm{C}$ for $90 \mathrm{~s}$, and a final extension at $72^{\circ} \mathrm{C}$ for $10 \mathrm{~min}$ (Lee et al., 2008). 


\section{RESULTS}

\section{Maintaining ability of 5 maintainers}

The pollen quantity and the self-crossed fruit-setting rate of $\mathrm{F} 1$ hybrids from each crosscombination (A x B) were observed in the field to grossly predict the maintaining ability of the maintainers in each CMS line. The self-crossed fruit-setting rate of M45, M7, M28, M9, M1, and M2 were nil and these 6 F1 hybrids did not have normal pollen or traces of pollen, which indicated that the $6 \mathrm{~F} 1$ hybrids were sterile and that the sterility could be maintained in the mating of 200A x 206B, 201 A x 206B, 201 A x 200B, 203A x 200B, 206A x 200B, and 206A x 201B. However, it was observed that M3, M18, M30, and M41 did not have pollen or traces of pollen, with both their self-crossed fruit-setting rate less than $20 \%$. These findings demonstrated that the 4 F1 hybrids were partially fertile, thus the fertility of the 4 was relatively low (Table 3 ).

\begin{tabular}{|c|c|c|c|c|c|c|c|c|c|c|c|}
\hline \multirow[t]{2}{*}{ Code } & \multicolumn{3}{|c|}{ Number } & \multirow{2}{*}{$\begin{array}{l}\text { Self-crossed fruit-setting } \\
\quad \text { rate }(\text { means } \pm \mathrm{SE})\end{array}$} & \multirow[t]{2}{*}{ Fertility } & \multirow[t]{2}{*}{ Code } & \multicolumn{3}{|c|}{ Number } & \multirow{2}{*}{$\begin{array}{l}\text { Self-crossed fruit-setting } \\
\quad \text { rate (means } \pm \mathrm{SE} \text { ) }\end{array}$} & \multirow[t]{2}{*}{ Fertility } \\
\hline & ++ & +- & - & & & & ++ & +- & - & & \\
\hline M1 & 0 & 0 & 36 & $0.00 \pm 0.00$ & $\mathrm{~S}$ & M28 & 0 & 0 & 36 & $0.00 \pm 0.00$ & $\mathrm{~S}$ \\
\hline M2 & 0 & 0 & 38 & $0.00 \pm 0.00$ & $\mathrm{~S}$ & M29 & 0 & 32 & 0 & $32.00 \pm 11.36$ & $\mathrm{~F}$ \\
\hline M3 & 0 & 0 & 30 & $13.00 \pm 5.75$ & $\mathrm{PF}$ & M30 & 0 & 0 & 35 & $5.00 \pm 0.27$ & $\mathrm{PF}$ \\
\hline M7 & 0 & 0 & 21 & $0.00 \pm 0.00$ & $\mathrm{~S}$ & M42 & 0 & 0 & 32 & $26.00 \pm 10.75$ & $\mathrm{~F}$ \\
\hline M8 & 0 & 32 & 12 & $26.00 \pm 8.75$ & $\mathrm{~F}$ & M43 & 38 & 0 & 0 & $27.00 \pm 9.49$ & $\mathrm{~F}$ \\
\hline M9 & 0 & 0 & 24 & $0.00 \pm 0.00$ & $\mathrm{~S}$ & M44 ${ }^{\mathrm{a}}$ & 0 & 37 & 0 & $43.00 \pm 9.49$ & $\mathrm{~F}$ \\
\hline M10 & 22 & 0 & 0 & $46.00 \pm 13.50$ & $\mathrm{~F}$ & M45 & 0 & 0 & 39 & $0.00 \pm 0.00$ & $\mathrm{~S}$ \\
\hline M15 & 38 & 0 & 0 & $14.00 \pm 5.67$ & $\mathrm{~F}$ & M46 & 38 & 0 & 0 & $14.00 \pm 7.00$ & $\mathrm{~F}$ \\
\hline M18 & 0 & 0 & 34 & $14.00 \pm 5.67$ & $\mathrm{PF}$ & $\mathrm{M} 41^{\mathrm{a}}$ & 0 & 0 & 39 & $7.00 \pm 0.75$ & $\mathrm{PF}$ \\
\hline
\end{tabular}

$(++)=$ pollen quantity basically equal to that of the male parent; $(+-)=$ pollen quantity basically equal to $50 \%$ of the male parent; $(-)=$ traces of pollen grains or no pollen; $\mathrm{SE}=$ standard error; $\mathrm{F}=$ fertile; $\mathrm{S}=$ sterile; $\mathrm{PF}=$ partially fertile; ano seed.

The indoor tests of pollen quantity, pollen germination of each anther, and the number of seeds in each fruit revealed that F1 hybrids M18, M41, M44, M45, M7, M28, M9, M1, and M2 could not seed, thereby suggesting the sterility of the plants. These findings indicated that sterility could be maintained in the mating of 200A x 201B, 200A x 202B, 200A x 203B, 200A x 206B, 201A x 200B, 201A x 206B, 206A x 200B, 203A x 200B, and 206A x 201B. Other F1 hybrids of the crosscombinations $(\mathrm{A} \times \mathrm{B}$ ) were fertile, thus indicating no maintaining ability of the male parent (Table 4).

The field survey and indoor test showed that different maintainers had different maintaining ability to the same CMS line, although the same maintainer had different maintaining ability to different CMS lines, such as the maintaining ability of 200B to 201A, 203A, and $206 \mathrm{~A}$, just as that of $201 \mathrm{~B}$ to $206 \mathrm{~A}$ and $206 \mathrm{~B}$ to $200 \mathrm{~A}$ and $201 \mathrm{~A}$. However, sterility could not be maintained in the mating of 203A x 201B, 203A x 202B, 206A x 202B, 201A x 203B, 206A x 203B, 202A x 206B, and 203A x 206B. Of note, M3, M18, M30, and M41 were partially fertile, as M3 and M30 had traces of pollen grains and lower than 20\% self-crossed fruit-setting rates (Figure 1), although they had a few seeds in the fruit; the pollen was also viable. These results showed that 201B and 202B, the male parents of M3 and M30, could not maintain the sterility of 202A and 201A, respectively. In addition, M18 and M41 had a small quantity of pollen 
and their fruit-setting rates were lower than $20 \%$ in the field; however, their fruits had no seeds while the pollen quantity, pollen germination of each anther, and the number of seeds in each fruit were both practically nil according to the indoor test. These results suggested that M18 and M41 were sterile, thus 201B and 202B, the male parents of M18 and M41, respectively, could maintain the sterility of 200A. Moreover, by field survey, M44 had pollen to some extent and could yield fruit by self-pollination, while the number of its seeds was nil despite the viable pollen. Therefore, M44 was sterile, thus indicating that 203B could maintain the sterility of 200A.

Table 4. Pollen quantity, germination rate, and the number of the seed in F1 hybrid of cytoplasmic male sterility lines and maintainers in pepper.

\begin{tabular}{lccrcccccc}
\hline Code & $\begin{array}{c}\text { Pollen quantity } \\
\text { (means } \pm \text { SE) }\end{array}$ & $\begin{array}{c}\text { Germination } \\
\text { rate }(\%)\end{array}$ & Seed No. & Fertility & Code & $\begin{array}{c}\text { Pollen quantity } \\
\text { (means } \pm \text { SE) }\end{array}$ & $\begin{array}{c}\text { Germination } \\
\text { rate }(\%)\end{array}$ & Seed No. & Fertility \\
\hline M18 & $0 \pm 0$ & $0.00 \pm 0.00$ & $0.00 \pm 0.00$ & S & M10 & $41921 \pm 1639$ & $52.50 \pm 3.54$ & $43.40 \pm 7.61$ & $\mathrm{~F}$ \\
M41 & $0 \pm 0$ & $0.00 \pm 0.00$ & $00.00 \pm 0.00$ & S & M9 & $3848 \pm 612$ & $0.00 \pm 0.00$ & $0.00 \pm 0.00$ & S \\
M44 & $11152 \pm 1581$ & $44.81 \pm 5.01$ & $0.00 \pm 0.00$ & S & M43 & $12500 \pm 1936$ & $57.14 \pm 15.54$ & $44.50 \pm 6.64$ & $\mathrm{~F}$ \\
M45 & $3466 \pm 503$ & $0.00 \pm 0.00$ & $0.00 \pm 0.00$ & S & M8 & $13269 \pm 2172$ & - & $58.40 \pm 7.11$ & F \\
M7 & $2900 \pm 200$ & $0.00 \pm 0.00$ & $0.00 \pm 0.00$ & S & M42 & $2803 \pm 488$ & - & $54.78 \pm 7.34$ & F \\
M30 & $3464 \pm 681$ & $51.67 \pm 6.86$ & $18.00 \pm 5.93$ & F & M1 & $0 \pm 0$ & $0.00 \pm 0.00$ & $0.00 \pm 0.00$ & S \\
M29 & $9358 \pm 413$ & $66.60 \pm 25.51$ & $38.00 \pm 7.02$ & F & M2 & $22238 \pm 2129$ & $0.00 \pm 0.00$ & $0.00 \pm 0.00$ & S \\
M28 & $916 \pm 72$ & $0.00 \pm 0.00$ & $0.00 \pm 0.00$ & S & M46 & $19166 \pm 2714$ & $49.39 \pm 11.76$ & $54.90 \pm 9.64$ & F \\
M3 & $2955 \pm 787$ & $50.98 \pm 10.14$ & $37.60 \pm 6.70$ & F & M15 & $36924 \pm 4306$ & $43.33 \pm 2.36$ & $78.80 \pm 11.82$ & F \\
\hline
\end{tabular}

$\mathrm{SE}=$ standard error; $\mathrm{F}=$ fertile; $\mathrm{S}=$ sterile; $(-)=$ deficit.

\section{A}

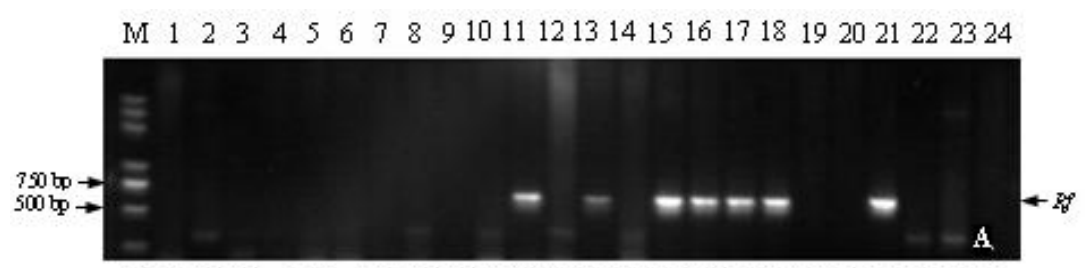

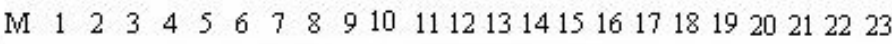

B

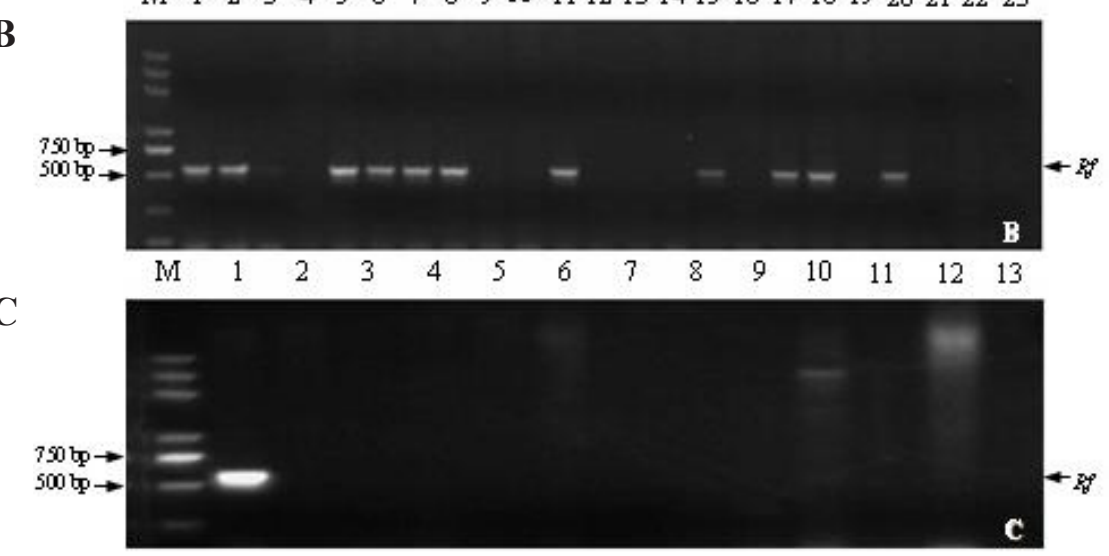

Figure 1. PCR amplification of $R f$-linked CRF-SCAR DNA marker in the parents and their F1 hybrids. Lane $M=$ Trans 2K plus DNA ladder marker. A. Lanes 1 to $24=$ M10, M1, M2, M3, M4, M5, M6, M7, M8, M9, M11, M12, M13, 206B, M15, M16, 207C, 208C, 209C, 211C, 213C, 214C, 200A, and 200B. B. Lanes 1 to 23= M26, M33, M38, M18, M19, M20, M21, M22, M23, M24, M25, M28, M29, M30, M31, M34, M35, M36, M37, M39, M40, M41, and M42. C. Lanes 1 to 13 = M14, M43, M44, M45, M46, 201A, 201B, 202A, 202B, 203A, 203B, 204A, and 206A. 


\section{Restoring ability of 6 restorers}

The pollen quantity and spontaneous fruit-setting rate of F1 hybrids in each combination (A x C) tested in the field showed that M37 and M24 did not have viable pollen or traces of pollen, with no self-crossed fruit-setting. These findings indicated that $213 \mathrm{C}$ could not restore the fertility of 200A and 204A (Table 5). M21 and M31 were partially fertile, with lower than $20 \%$ self-crossed fruit-setting rates, $11.00 \pm 5.68$ and $10.00 \pm 6.67 \%$, respectively, indicating that $209 \mathrm{C}$ and $214 \mathrm{C}$ had relatively low restoring ability to 204A. Other F1 hybrids of the cross-combinations $(\mathrm{A} \times \mathrm{C})$ were fertile.

\begin{tabular}{|c|c|c|c|c|c|c|c|c|c|c|c|}
\hline \multirow[t]{2}{*}{ Code } & \multicolumn{3}{|c|}{ Number } & \multirow{2}{*}{$\begin{array}{l}\text { Self-crossed fruit-setting } \\
\text { rate }(\%, \text { means } \pm \text { SE) }\end{array}$} & \multirow[t]{2}{*}{ Fertility } & \multirow[t]{2}{*}{ Code } & \multicolumn{3}{|c|}{ Number } & \multirow{2}{*}{$\begin{array}{l}\text { Self-crossed fruit-setting } \\
\text { rate }(\%, \text { means } \pm \text { SE) }\end{array}$} & \multirow[t]{2}{*}{ Fertility } \\
\hline & ++ & +- & - & & & & ++ & +- & - & & \\
\hline M5 & 38 & 0 & 0 & $23.00 \pm 6.75$ & $\mathrm{~F}$ & M31 & 38 & 0 & 0 & $10.00 \pm 6.67$ & PF \\
\hline M11 & 40 & 0 & 0 & $48.00 \pm 10.33$ & $\mathrm{~F}$ & M33 & 33 & 0 & 0 & $48.00 \pm 13.17$ & $\mathrm{~F}$ \\
\hline M13 & 38 & 0 & 0 & $38.00 \pm 15.49$ & $\mathrm{~F}$ & M34 & 35 & 0 & 0 & $49.00 \pm 11.97$ & $\mathrm{~F}$ \\
\hline M14 & 34 & 0 & 0 & $34.00 \pm 12.65$ & $\mathrm{~F}$ & M35 & 37 & 0 & 0 & $44.00 \pm 9.67$ & $\mathrm{~F}$ \\
\hline M16 & 42 & 0 & 0 & $42.00 \pm 12.29$ & $\mathrm{~F}$ & M36 & 37 & 0 & 0 & $37.00 \pm 9.49$ & $\mathrm{~F}$ \\
\hline M19 & 34 & 0 & 0 & $50.00 \pm 11.55$ & $\mathrm{~F}$ & M37 & 0 & 0 & 35 & $0.00 \pm 0.00$ & $\mathrm{~S}$ \\
\hline M20 & 0 & 32 & 0 & $55.00 \pm 8.50$ & $\mathrm{~F}$ & M38 & 37 & 0 & 0 & $33.00 \pm 9.49$ & $\mathrm{~F}$ \\
\hline M21 & 40 & 0 & 0 & $11.00 \pm 5.68$ & $\mathrm{PF}$ & M39 & 0 & 0 & 30 & $23.00 \pm 12.52$ & $\mathrm{~F}$ \\
\hline M22 & 38 & 0 & 0 & $47.00 \pm 9.49$ & $\mathrm{~F}$ & M40 & 33 & 0 & 0 & $61.00 \pm 11.92$ & $\mathrm{~F}$ \\
\hline $\mathrm{M} 23$ & 32 & 0 & 0 & $31.00 \pm 7.38$ & $\mathrm{~F}$ & M24 & 0 & 0 & 44 & $0.00 \pm 0.00$ & $\mathrm{~S}$ \\
\hline M26 & 32 & 0 & 0 & $25.00 \pm 7.07$ & $\mathrm{~F}$ & M25 & 35 & 0 & 0 & $25.00 \pm 10.80$ & $\mathrm{~F}$ \\
\hline
\end{tabular}

$(++)=$ pollen quantity basically equal to that of the male parent; $(+-)=$ pollen quantity basically equal to $50 \%$ of the male parent; $(-)=$ traces of pollen grains or no pollen; $\mathrm{SE}=$ standard error; $\mathrm{F}=$ fertile; $\mathrm{S}=$ sterile; $\mathrm{PF}=$ partially fertile.

The seeds per fruit of M24 and M37 were found to be practically nil (Table 6), indicating sterility, as $213 \mathrm{C}$ could not restore the fertility of $200 \mathrm{~A}$ and $204 \mathrm{~A}$. The number of seeds per fruit of M23 was lower, approximately $11.20 \pm 4.67$, indicating that $211 \mathrm{C}$ had decreased restoring ability to 204A. Furthermore, the pollen quantity of M39 and M31 was lower than that of the male parent (restorer), 4,609 \pm 309 and 1,675 \pm 168 , respectively. Therefore, the restoring abilities of $207 \mathrm{C}$ to $203 \mathrm{~A}$ and $214 \mathrm{C}$ to $204 \mathrm{~A}$ are decreased.

Table 6. Pollen quantity, germination rate, and number of the seeds in F1 hybrid of cytoplasmic male sterility lines and restorers in pepper.

\begin{tabular}{|c|c|c|c|c|c|c|c|c|c|}
\hline Code & $\begin{array}{l}\text { Pollen quantity } \\
\text { (means } \pm \mathrm{SE} \text { ) }\end{array}$ & $\begin{array}{l}\text { Germination } \\
\text { rate }(\%)\end{array}$ & Seed No. & Fertility & Code & $\begin{array}{l}\text { Pollen quantity } \\
(\text { means } \pm \text { SE) }\end{array}$ & $\begin{array}{l}\text { Germination } \\
\text { rate }(\%)\end{array}$ & Seed No. & Fertility \\
\hline M19 & $45,699 \pm 3514$ & $39.36 \pm 1.25$ & $51.80 \pm 8.55$ & $\mathrm{~F}$ & M38 & $36,950 \pm 1977$ & $41.19 \pm 9.21$ & $57.30 \pm 4.85$ & $\mathrm{~F}$ \\
\hline M22 & $29,768 \pm 1586$ & $89.52 \pm 5.39$ & $36.30 \pm 5.17$ & $\mathrm{~F}$ & M36 & $23,108 \pm 4190$ & $52.63 \pm 16.76$ & $136.90 \pm 26.92$ & $\mathrm{~F}$ \\
\hline M33 & $52,576 \pm 2092$ & $40.68 \pm 8.53$ & $53.70 \pm 7.09$ & $\mathrm{~F}$ & M40 & $53,265 \pm 1774$ & $45.56 \pm 5.10$ & $78.80 \pm 5.18$ & $\mathrm{~F}$ \\
\hline M5 & $65,494 \pm 4742$ & $41.14 \pm 6.09$ & $45.30 \pm 5.27$ & $\mathrm{~F}$ & M34 & $42,295 \pm 2639$ & $59.89 \pm 6.32$ & $44.4 \pm 4.01$ & F \\
\hline M24 & - & $50.11 \pm 28.52$ & $0.00 \pm 0.00$ & S & M26 & $24,404 \pm 2572$ & $26.06 \pm 5.13$ & $92.4 \pm 8.75$ & $\mathrm{~F}$ \\
\hline M35 & $51,598 \pm 1840$ & $81.53 \pm 9.21$ & $69.80 \pm 6.21$ & $\mathrm{~F}$ & M25 & $50,568 \pm 3841$ & $44.29 \pm 2.02$ & $31.1 \pm 8.72$ & F \\
\hline M14 & $34,816 \pm 3679$ & $54.89 \pm 16.73$ & $38.20 \pm 2.97$ & F & M20 & $9,700 \pm 786$ & $48.85 \pm 21.25$ & $59.60 \pm 5.25$ & F \\
\hline M13 & - & $46.42 \pm 19.76$ & $67.7 \pm 6.95$ & $\mathrm{~F}$ & M21 & $21,487 \pm 1420$ & $59.46 \pm 16.37$ & $54.20 \pm 8.12$ & F \\
\hline M11 & $36,950 \pm 3163$ & - & $60.30 \pm 5.27$ & $\mathrm{~F}$ & M23 & $37,833 \pm 2468$ & $36.57 \pm 16.63$ & $11.20 \pm 4.67$ & F \\
\hline M16 & $44,340 \pm 2306$ & $82.14 \pm 13.25$ & $77.80 \pm 5.83$ & $\mathrm{~F}$ & M37 & $3,628 \pm 608$ & $47.78 \pm 13.47$ & $0.00 \pm 0.00$ & S \\
\hline M39 & $4,609 \pm 309$ & $21.25 \pm 12.37$ & $48.7 \pm 6.22$ & $\mathrm{~F}$ & M31 & $1,675 \pm 168$ & $41.11 \pm 1.92$ & $39.80 \pm 8.85$ & $\mathrm{~F}$ \\
\hline
\end{tabular}

$\mathrm{SE}=$ standard error; $\mathrm{F}=$ fertile; $\mathrm{S}=$ sterile; $(-)=$ deficit. 
The findings described above showed that all of the restorers tested in our experiments could restore the fertility of all of the CMS lines tested, with the exception that $213 \mathrm{C}$ could not restore the fertility of $200 \mathrm{~A}$ and $204 \mathrm{~A}$. However, the restoring ability of the different restorers differed; this finding was primarily exemplified in the pollen quantity, pollen germination, fruit-setting rates, and seeds per fruit of the F1 progeny in the cross-combination (the same restorer to different CMS lines). It is worth noting that the self-crossed fruit-setting rate of M21 was only $11.00 \pm 5.68 \%$, while the pollen quantity, pollen germination, and seeds per fruit indicated that M21 was fertile; therefore, 209C could restore the fertility of $204 \mathrm{~A}$, while the low fruit-setting rate might be due to the lower vitality of the pistil. The self-crossed fruit-setting rates of M39 with decreased pollen quantity and germination, M31 with decreased pollen quantity, and M23 with fewer seeds per fruit were $23.00 \pm 12.52,10.00 \pm 6.67$, and $31.00 \pm 7.38 \%$, respectively. These results indicate that $211 \mathrm{C}$ and $214 \mathrm{C}$ may have worse restoring ability to $204 \mathrm{~A}$, as did $207 \mathrm{C}$ to $203 \mathrm{~A}$.

\section{Analysis of the $R f$-linked DNA marker}

The CMS lines, maintainers, and their F1 individuals were polymorphic for the $R f$ linked DNA marker, CRF-SCAR. The CRF-SCAR marker was reported to be linked to the major $R f$ locus at the distance of $5 \mathrm{cM}$. The presence of the CRF-SCAR PCR product was associated with the presence of the $R f$ allele. The results of the present study showed that the CRF-SCAR PCR product was only present in M15, which indicated that M15 (206A x 203B) has the $R f$ gene; however, we could not amplify any objective PCR product in 206A and 203B, which may have resulted from gene rearrangement caused by the crossing of parents, and further study is warranted to investigate the specific cause.

In the 6 restorers tested, the $R f$ gene was polymorphic for the presence of the CRF-SCAR PCR product, and only occurred in 207C, 208C, and 213C. Further studies are required to determine the mechanisms involved in controlling the restoring ability of restorers.

The CRF-SCAR PCR product was also found in M39 (203A x 207C), M14 (202A x 207C), M19 (200A x 207C), M25 (204A x 207C), M13 (202A x 208C), M20 (204A x 208C), and M22 (200A x 208C), the F1 hybrids of CMS lines and restorers, and also the male parents $207 \mathrm{C}$ and $208 \mathrm{C}$. These results may indicate that $207 \mathrm{C}$ and $208 \mathrm{C}$ can transmit the $R f$-linked marker or the $R f$ gene to $\mathrm{F} 1$ hybrids.

Although there was no CRF-SCAR PCR product in 209C and 214C, the CRF-SCAR marker was present in the F1 hybrids M33 (200A x 209C), M11 (202A x 209C), M21 (204A x 209C), M36 (203A x 209C), M35 (200A x 214C), M16 (202A x 214C), M26 (203A x 214C), and M31 (204A x 214C). These results might be due to the nucleo-cytoplasmic interactions of CMS lines and restorers in pepper.

In M5, M40, and M23 as well as their male parents such as 211C, no PCR product was found, although $211 \mathrm{C}$ could restore the fertility of 200A, 203A, and 204A. These findings may be related to the genetic diversity of the $R f$ gene. Taken together, these data demonstrated that genetic differences of the $R f$ gene exist in different materials (Figure 2). 


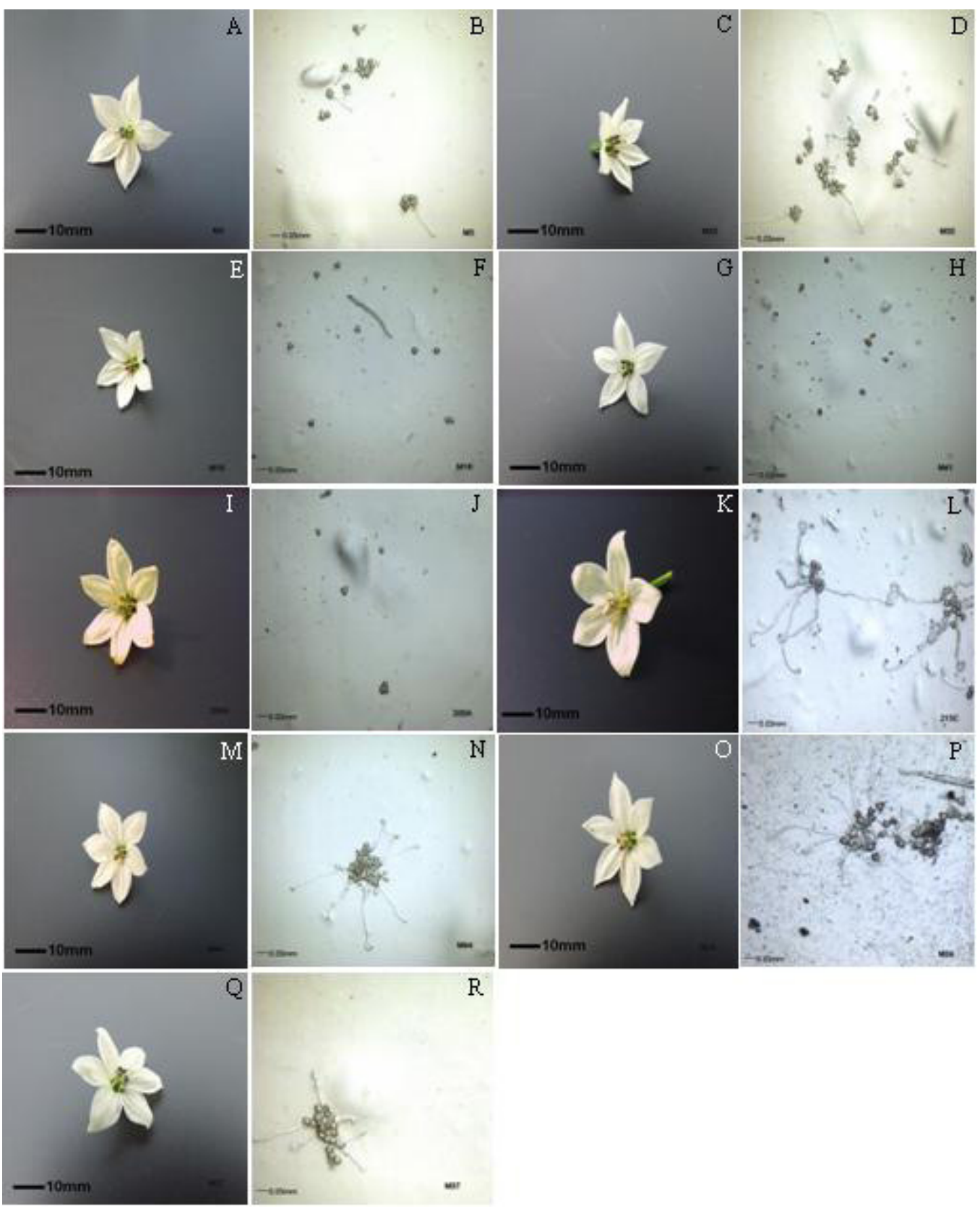

Figure 2. Pollen germination and the morphological characters of the flower in the parents and their F1 hybrids. A. C. E. G. I. K. M. O. and Q. Morphological characters of the flower of M3, M30, M18, M41, 200A, 213C, M44, M24, and M37, respectively, bar $=10 \mathrm{~mm}$. B. D. F. H. J. L. N. P. and R. Pollen germination of M3, M30, M18, M41, 200A, 213C, M44, M24, and M37, respectively, bar $=0.03 \mathrm{~mm}$. 


\section{DISCUSSION}

It is thought that the differences of maintaining ability are caused by the different sources of the cytoplasm and nucleolus (Wang et al., 2009). Our studies of the relationship of CMS lines, maintainers, and restorers revealed that a same maintainer had different maintaining ability to the CMS lines with different sources of cytoplasm; for example, 201B could maintain the sterility of 201A and 206A and partially maintain the sterility of 200A, while it could not maintain the sterility of $202 \mathrm{~A}$ and $203 \mathrm{~A}$. In addition, different maintainers had different maintaining ability to the same CMS line; for instance, 200B might completely maintain the sterility of 201A, 203A, and 206A, while 202B did not have any maintaining ability to 201A, 203A, and 206A. These results were similar to those of rice (Wang et al., 2009). The crossing test between CMS lines and restorers in pepper demonstrated that different restorers had different restoring ability to the same CMS line; for instance, 207C, $208 \mathrm{C}$, and $209 \mathrm{C}$ could restore the adequately fertility of $204 \mathrm{~A}$, while $211 \mathrm{C}$ and $214 \mathrm{C}$ had worse restoring ability to $204 \mathrm{~A}$. We inferred that it was the variation in the $R f$ genes of the restorers that might lead to these differences. Furthermore, the same restorer had different restoring ability to the CMS lines with different sources of cytoplasm; for example, 214C had better restoring ability to $200 \mathrm{~A}$, but had worse restoring ability to 204A. This might be explained by the different cytoplasm leading to the differences of the restoring ability among the CMS lines with the same nucleolus (Tang et al., 2005).

The pairs of $R f$ genes are different among the different restorers of radish (Zhang et al., 2002), with some radishes having 1 pair and others having 2 pairs. Our experiment revealed that different maintainers and restorers might carry different $R f$ genes and different pairs of alleles (Table 7). The complexity of the differentiation of the cytoplasm and nucleolus with different sources in addition to the difference of the regions may likely result in the diversity of nuclear genes.

Table 7. Genotypes and function of cytoplasmic male sterility three-lines in pepper.

\begin{tabular}{|c|c|c|c|c|}
\hline Line & Original genotype & Previous line function & Complete cytoplasm and nuclear genotypes & New line function \\
\hline $200 \mathrm{~A}$ & $S m s_{0} m s_{0}$ & A line & $S m s_{0} m s_{0} m s_{1} m s_{1} m s_{3} m s_{3} m s_{6} m s_{6}$ & A line of $m s_{0}$ \\
\hline $201 \mathrm{~A}$ & $S m s m s$ & A line & $\mathrm{Sms}_{0} m s_{0} m s_{1} m s_{1} M s_{2} M s_{2} M s_{3} M s_{3} m s_{6} m s_{6}$ & A line of $m s$ \\
\hline $202 \mathrm{~A}$ & $\mathrm{Sms}_{2} m s_{2}$ & A line & $S m s_{0} m s_{0} M s_{2} M s_{1} m s_{2} m s_{2} M s_{3} M s_{3} M s_{6} M s_{6}$ & A line of $m s_{2}$ \\
\hline $203 \mathrm{~A}$ & $\mathrm{Sms}_{3} \mathrm{~ms}_{3}{ }^{2}$ & A line & $S m s_{0} m s_{0} M s_{1} M s_{1} m s_{3} m s_{3}^{2} M s_{6} M s_{6}$ & A line of $m s_{3}^{2}$ \\
\hline $204 \mathrm{~A}$ & $\mathrm{Sms}_{4}^{3} m s_{4}^{3}$ & A line & 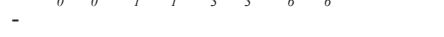 & A line of $m s_{4}^{3}$ \\
\hline $206 \mathrm{~A}$ & $S m s_{6}^{4} m s_{6}^{4}$ & A line & $S m s_{0} m s_{0} m s_{1} m s_{1} M s_{2} M s_{2} M s_{3} M s_{3} m s_{6} m s_{6}$ & A line of $m s_{6}^{4}$ \\
\hline 200B & $N m s_{0} m s_{0}$ & B line & $N m s_{0} m s_{0} m s_{I} m s_{I} m s_{3} m s_{3} m s_{6} m s_{6}$ & B line of $m_{0}, m s_{1}, m s_{3}$, and $m s_{6}$ \\
\hline 201B & $N m s_{l} m s_{l}$ & B line & $N m s_{0} m s_{0} m s_{1} m s_{1} M s_{2} M s_{2} M s_{3} M s_{3} m s_{6} m s_{6}$ & $\begin{array}{l}\text { B line of } m s_{0}, m s_{1}, \text { and } m s_{6} \\
\text { C line of } m s_{2}, m s_{3}\end{array}$ \\
\hline 202B & $\mathrm{Nms}_{2} m s_{2}$ & B line & $N m s_{0} m s_{0} M s_{1} M s_{1} m s_{2} m s_{2} M s_{3} M s_{3} M s_{6} M s_{6}$ & $\begin{array}{l}\text { B line of } m s_{0}, m s_{2} \\
\mathrm{C} \text { line of } m s_{l}, m s_{3} \text {, and } m s_{6}\end{array}$ \\
\hline 203B & $\mathrm{Nms}_{3} m s_{3}$ & B line & $N m s_{0} m s_{0} M s_{1} M s_{1} m s_{3} m s_{3} M s_{6} M s_{6}$ & $\begin{array}{l}\text { B line of } m s_{0}, m s_{3} \\
\text { C line of } m s_{1}, m s_{6}\end{array}$ \\
\hline 206B & $N m s_{6} m s_{6}$ & B line & $N m s_{0} m s_{0} m s_{1} m s_{1} M s_{2} M s_{2} M s_{3} M s_{3} m s_{6} m s_{6}$ & $\begin{array}{l}\text { B line of } m s_{0}, m s_{1}, \text { and } m s_{6} \\
\text { C line of } m s_{2}, m_{3}\end{array}$ \\
\hline $207 \mathrm{C}$ & $N R f_{7} R f_{7}$ & $\mathrm{C}$ line & $N R f_{7} R f_{7} M s_{0} M s_{0} M s_{2} M s_{2} M s_{3} M s_{3} M s_{4} M s_{4}$ & $\mathrm{C}$ line of $m s_{0}, m s_{2}, m s_{3}$, and $m s_{4}$ \\
\hline $208 \mathrm{C}$ & $N R f_{8} R f_{8}$ & $\mathrm{C}$ line & $\mathrm{NRf}_{8} R f_{8} M s_{0} M s_{0} M s_{2} M s_{2} M s_{3} M s_{3} M s_{4} M s_{4}$ & $\mathrm{C}$ line of $m s_{0}, m s_{2}, m s_{3}$, and $m s_{4}$ \\
\hline $209 \mathrm{C}$ & $N R f_{9} R f_{9}$ & C line & $N R f_{9} R f_{9} M s_{0} M s_{0} M s_{2} M s_{2} M s_{3} M s_{3} M s_{4} M s_{4}$ & $\mathrm{C}$ line of $m s_{0}, m s_{2}, m s_{3}$, and $m s_{4}$ \\
\hline $211 \mathrm{C}$ & $N R f_{11} R f_{11}$ & $\mathrm{C}$ line & $N R f_{1 !} R f_{I I} M s_{0} M s_{0} M s_{3} M s_{3} M s_{4} M s_{4}$ & $\mathrm{C}$ line of $m s_{0}, m s_{3}$, and $m s_{4}$ \\
\hline $213 \mathrm{C}$ & $N R f_{13} R f_{13}$ & $\mathrm{C}$ line & $N R f_{13} R f_{13} m s_{0} m s_{0} M s_{3} M s_{3} m s_{4} m s_{4}$ & $\mathrm{C}$ line of $m s_{3}, \mathrm{~B}$ line of $m s_{3}$, and $m s_{4}$ \\
\hline $214 \mathrm{C}$ & $S R f_{14} R f_{14}$ & C line & $S R f_{14} R f_{14} M s_{0} M s_{0} M s_{2} M s_{2} M s_{3} M s_{3} M s_{4} M s_{4}$ & $\mathrm{C}$ line of $m s_{0}, m s_{2}, m s_{3}$, and $m s_{4}$ \\
\hline
\end{tabular}


In practical breeding, the adaptive capacity of a same type of CMS line in one crop is limited. Hence, it is necessary to select and breed several types of CMS lines and their related restorers for improving the resistance and stability of the yield of F1 hybrids (Liu et al., 2011). The genotypes of the 5 CMS lines in our study were different, and difference also existed in the maintainers and restorers (Table 7). These findings provide the foundation for further study and use of these rare plant materials.

\section{CONCLUSIONS}

The present study of the relationship between maintaining and restoring among different CMS systems revealed the maintaining ability of the maintainers to the CMS lines and also the restoring ability of the restorers to the CMS lines. In addition, the detection of the $R f$-linked marker among all of the plant materials showed the inheritance of the $R f$ gene between the male parent, 207C, $208 \mathrm{C}$, and the F1 hybrid. As there was a consistent relationship of maintaining in some CMS lines with different cytoplasm, it is possible to breed many sterile lines with the same nucleus to exploit this cytoplasmic diversity; additionally, the different restoring ability of the restorers may indicate that there are other unknown $R f$ genes in pepper. In future studies, some other new $R f$ genes may be found by analyzing the F2 segregations, which could enrich the genetic diversity of the restorers. These studies will promote the resistance of pepper to abiotic stresses encountered in practical production.

\section{ACKNOWLEDGMENTS}

Research supported by the National Natural Science Foundation of China (\#30771467), "The Twelfth Five-Year" Plan of National Science and Technology in Rural Areas (\#2011BAD12B00), and the Shaanxi Provincial Science and Technology Development Project (\#2011K02-09).

\section{REFERENCES}

Budar F, Touzet P and De Paepe R (2003). The nucleo-mitochondrial conflict in cytoplasmic male sterilities revisited. Genetica 117: 3-16.

Chase CD (2007). Cytoplasmic male sterility: a window to the world of plant mitochondrial-nuclear interactions. Trends Genet. 23: 81-90.

Gong ZH, Huang W and Lv YH (2008). A Method of Creating CMS Materials in Pepper. Patent No. ZL200510124552.4: 2008130.

Gulyas G, Pakozdik K, Lee JS and Hirata Y (2006). Analysis of fertility restoration by using cytoplasmic male-sterile red pepper (Capsicum annuum 1.) lines. Breed. Sci. 56: 331-334.

Guo XC (2001). How to understand nuclear DNA in cytoplasmic male sterlity. Chin. J. Appl. Environ. Biol. 7: 297-301.

Hanson MR (1991). Plant mitochondrial mutations and male sterility. Annu. Rev. Genet. 25: 461-486.

Hanson MR and Bentolila S (2004). Interactions of mitochondrial and nuclear genes that affect male gametophyte development. Plant Cell (Suppl 16): S154-S169.

Horn R (2006). Cytoplasmic male sterility and fertility restoration in higher plants. Prog. Bot. 67: 31-52.

Kim DH and Kim BD (2005). Development of SCAR markers for early identification of cytoplasmic male sterility genotype in chili pepper (Capsicum annuum L.). Mol. Cells 20: 416-422.

Kim DH, Kang JG, Kim S and Kim BD (2001). Identification of coxII and atp6 region as associated to CMS in Capsicum annuum by using RFLP and long accurate PCR. J. Korean Sci. 42: 121-127.

Lee JS, Lee KH, Kim YS, Kang KK, et al. (2004). Detection of individuals restoring fertility by DNA fragment converted into STS (sequence tagged site) in red pepper. Plant Resour. 8: 136-140. 
Lee J, Yoon JB and Park HG (2008). Linkage analysis between the partial restoration $(p r)$ and the restorer-of-fertility $(R f)$ loci in pepper cytoplasmic male sterility. Theor. Appl. Genet. 117: 383-389.

Linke B and Borner T (2005). Mitochondrial effects on flower and pollen development. Mitochondrion 5: 389-402.

Liu L, Li XR, Wang GH, Wang DC, et al. (2011). Breeding and molecular biology progress of male sterile pepper in China. Current Biotechnol. 1: 254-259.

Peterson PA (1958). Cytoplasmically inherited male sterility in Capsicum. Am. Nat. 92: 111-119.

Schnable PS and Wise RP (1998). The molecular basis of cytoplasmic male sterility and fertility restoration. Trends Plant Sci. 3: 175-180.

Shifriss C (1997). Male sterility in pepper (Capsicum annuum L.). Euphytica 93: 83-88.

Shifriss C and Guri A (1979). Variation in stability of cytoplasmic male sterility in C. annuum L. J. Am. Soc. Hortic. Sci. 104: 94-96.

Tang SZ, Sun Y, Zhang HG, Gu YJ, et al. (2005). Comparison on the characteristics of the isonuclear alloplasmic CMS lines in japonica rice. Chin. J. Rice Sci. 19: 521-526.

Walbot V and Warren C (1988). Regulation of $M u$ element copy number in maize lines with an active or inactive Mutator transposable element system. Mol. Gen. Genet. 211: 27-34.

Wang XJ, Chen YJ, Zhang C, Ding F, et al. (2009). Comparative study on restorer and maintainer relation of CMS-FA hybrid rice in northern area. North Rice 40: 6-10.

Wang YX, Wang Y, Li FD, Wei X, et al. (2008). Study of pollen quantity and vitality of hawthorn cultivars with different kernel percentage. Shandong Agric. Sci. 2: 8-10.

Ye ZW, Du JH, Su MS, Li LL, et al. (2010). Cluster analysis for the quantity and germinating characteristics of the pollens from 92 peach cultivars. Acta Hortic. Sin. 37: 525-531.

Zhang BX, Huang SW, Yang GM and Guo JZ (2000). Two RAPD markers linked to a major fertility restorer gene in pepper. Euphytica 113: 155-161.

Zhang L, Wei Y, Li XY and Gong GY (2002). Inheritance of restoring genes for cytoplasmic-nucleus male sterility in radish (Raphanus sativus L.). Acta Hortic. Sin. 29: 326-328. 